\title{
artigo
}

\section{A estrutura de poder, 0 paternalismo e o papel da assessoria técnica gerencial na pequena empresa industrial ${ }^{*}$}

\section{Déa Lúcia Pimentel Teixeira Professora das disciplinas introducāo à administração $e$ teoria das organizaçôes do curso de graduação em economia e cursos de especialização na Universidade Estadual de Campinas (Unicamp).}

A organização das relações de trabalho na indústria reflete, basicamente, a forma de estruturação da sociedade global. E por meio dessa reprodução das condições de produção que é assegurada a sobrevivência e a expansão de qualquer formação social no modo de produção capitalista.

Portanto, a origem dos aspectos particulares da orga nização industrial, em nosso país, deve ser explicada, por um lado, em função das características que identificam o processo de formação e evolução do capitalismo no Brasil. E esse processo que, em suas distintas etapas, influencia, juntamente com os aspectos socio-políticos e culturais, a formação e o desempenho da classe proprietária dos meios de produção, principalmente em relação aos seus métodos de gerenciamento e dominação da mão-de-obra.

Por outro lado, são as caracterŕsticas da formação e evolução da organização da classe operária, no seu confronto com a classe empresarial, dentro do processo de desenvolvimento urbano-industrial, que também explicam as peculiaridades da organização das relações de trabalho.

A análise da pequena empresa industrial não foge a essa regra, pois, embora se saiba que a dinâmica do sistema econômico é dada pela grande empresa, a presença da pequena e média indústria é assegurada pelo grande capital no sentido de complementar ou suplementar sua ação.
Assim é que tais empresas cumprem um importante papel no sistema econômico, ao possibilitar a entrada de inúmeros investimentos individuais no mercado produtor e, nos momentos de ciclo descendente da economia, carrear esses pequenos capitais para os grandes empreendimentos, contribuindo para o processo de centralização do capital, ao mesmo tempo em que, recebendo os primeiros impactos das crises econômicas, resguardam os grandes empreendimentos, funcionando como um "colchão protetor".'

Além do mais, no plano social, respondem por elevada contribuição no sentido da manutenção do nivel de emprego, à medida que absorvem significativo volume de mão-de-obra do setor industrial, reduzindo, conseqüentemente, tensōes e conflitos que perturbam o desenvolvimento do modelo econômico.

A nivel de sua inserção nas estruturas de mercado, a pequena e média empresa exerce diferentes funções, cuja variação advém da etapa da evolução do sistema capitalista de produção e suas repercussões nas economias periféricas, assim como das necessidades e imposições do capital que, em última instância, exige um modo de organização e funcionamento do mercado mais adequado a sua expansão. De modo geral, essas funçōes consistem no preenchimento dos "espações vazios" das estruturas de mercado, isto é, nos segmentos de mercado onde a grande empresa não atua porque não existem vantagens resultantes de economias de escala.

Assim, são funçōes desempenhadas pela pequena e média empresa: atender a pequenos segmentos de mercado regionais e a pequenos mercados de produtos de caráter mais artesanal ou de luxo, além de produzir peças, componentes e realizar serviços para as empresas maiores, atuando então como produtor complementar.

Está implícito ainda nessa forma de abordagem o caráter do poder do qual se investem as relações sociais de trabalho nas empresas. Uma vez que se considera o capital como sendo "nada mais do que a expressão de um modo de relação entre os homens", no qual "uma classe social 'empreende', através de seus líderes, formas de dominar os homens a natureza no processo produtivo", 2 conclui-se que é por meio da constituição de uma estrutura de poder dentro da empresa que se obtém o controle do processo de produção e da mão-de-obra para que os objetivos visados pela classe empresarial sejam atingidos. Mas essa dominação de uma classe pela outra, para se viabilizar, tem que se legitimar.

Essa legit imação, devido às condições diferenciadas de inserção das empresas industriais nas estruturas de mercado, assume características também diferenciadas.

A grande empresa legitima sua estrutura de poder pelo caráter de impessoalidade, formalidade e profissionalismo, justificando esses meios adotados como os mais racionais para o alcance dos objetivos visados. É o tipo de legitimação racional-legal estudado e classificado por Weber. ${ }^{3}$ Essa forma organizacional burocrática é viabilizada pelas condições de acumulação que o porte propicia e, por sua vez, contribui para a ampliação dessa capacidade de acumulação e expansão, na medida em que possibilita a utilização de mecanismos de planejamento, controle e previsão mais precisos.

A pequena empresa industrial, no entanto, dadas suas características de inserção no mercado, não tem 
condiçðes de legitimar a dominação através de sua burocratização.

Uma vez que a prática administrativa, tipicamente burocrática, da grande empresa é inviável para as de pequeno porte, em função de sua complexidade e custos, a racionalidade administrativa dessas empresas assume formas mais simples e de menor custo, que atendem, momentaneamente, às suas necessidades básicas de sobrevivência.

Assim, assegura-se a submissão do trabalho ao capital, na pequena empresa, através da legitimação de uma estrutura de poder tradicional patrimonialista. ${ }^{4}$ Essa dominação está investida na figura do patrão, do dono, e é ampla e mal definida, pois diz respeito a outras relações que não só as funcionais.

O caráter da dominação é dado pela tradição. A pequena empresa, em geral, passa de pai para filho. As inovações ocorrem, porém parceladas e lentamente. Portanto, não ocorre a necessidade de registrar tudo por escrito. $\mathrm{O}$ costume, o hábito e a presença física encarregam-se das comunicaçôes e controle.

Nessa forma de organização do processo de trabalho, as atribuições são estabelecidas de momento a momento, com amplitude e conteúdo variados, a partir de critérios pessoais e, portanto, arbitrários. Neste sentido, caracteriza-se, mais uma vez, a impossibilidade da efetivação de registros escritos e objetivos.

A centralização que ocorre é justificada pelos empresários como necessária à agilização do processo decisório, como forma de redução dos custos e como modo de suprir a inexistência de pessoas aptas a assumir a delegação de tarefas.

Evidentemente, a falta de explicitação das atribujções, assim como a exigência de se tomar as decisōes à semelhança dos proprietários, são fatores que impedem - êxito na prática da delegação. Todas as demais opiniões são rechaçadas, uma vez que a orientação e a experiência patronais é que devem ser aceitas e valorizadas. A obediência dos subordinados deve-se dar em relação à pessoa do dono ou às de seus representantes $\mathrm{e}$, havendo discordância e conflitos, é esta opinião que prevalece.

$\mathrm{Na}$ realidade, a relutância em descentralizar representa a dúvida da possibilidade da perda do controle total sobre a empresa e a mão-de-obra. Pois somente o contato direto com os empregados e o conhecimento individual permitem, nesse porte de empresa, a efetivação do controle e também a veiculação da ideologia necessária para mascarar o conflito e promover a integração das duas classes para $o$ alcance dos objetivos empresariais.

E o paternalismo que cumpre esse papel de assegurar a dominação na pequena empresa. Não é opção. $O$ empresariado procura atender a certas necessidades dos subordinados ansiando por atitudes de gratidão e lealdade que, na realidade, exprimem a aceitação do domínio, por meio do esforço em corresponder às expectativas demonstradas pelos patrões em relação ao comportamento dos empregados e objetivos da empresa.

Nesse sentido, a aceitação se dá pelo dever de obediência e respeito à figura do patrão, aos privilégios que ele concede e retira quando bem lhe aprouver. Estruturase, pois, uma relação contratual de lealdade.

E esse controle direto aliado à ideologia empresarial que consegue da mão-de-obra produção, produtividade, aceitação e legitimação da dominação.
Por outro lado, a dedicação dos empregados ao trabalho, que é árduo e mal remunerado, e o esforço em procurar resolver os problemas de todos os tipos e a qualquer momento - o que pode ser traduzido pela capacidade de "quebra-galhos" - redundam, em seu favor, num critério de confiança dos empresários.

A subjetividade, portanto, impregna, necessariamente, toda a administração. $E$ a política de pessoal adotada demonstra este fato, claramente. Tudo é decidido em função do "caso a caso" e baseado fundamentalmente no tipo de comportamento demonstrado pelos empregados e nas emoções e sentimentos dos empresários. Os "bons" empregados, os "de confiança" têm seus privilégios e são valorizados. "Injustiça seria tratar todos da mesma forma", é a opiniáo de um empresário. E o padrão de comportamento esperado nada tem a ver com competência e habilitação, mas diz respeito a atitudes de gratidão e lealdade que propiciam retribuições efetivas.

$\mathrm{Na}$ verdade, essa subjetividade, que é uma faceta do paternalismo, nada tem de aleatória, mas significa a forma pela qual se obtém uma total dependência da mão-de-obra em relação à classe empresarial, com sérias conseqüências repressivas, uma vez que reduz o grau de reivindicações dos empregados e abafa as formas de explicitação dos conflitos. Por outro lado, contribui para resolver os problemas da redução de custos da empresa, pois incentiva à eficiência a partir de relações de amizade e compadresco, e da criação de imagem e ideais comuns.

$E$ através da ideologia empresarial reforça-se essa dominação.

Depreciar as atitudes dos empregados e sua formação, desvalorizar sua capacidade de trabalho e suas atividades constituem-se em maneiras de pensar comuns aos empresários, que na prática funcionam no sentido de rebaixar salários e reforçar a estrutura de poder patrimonial. Isto ocorre na medida em que é reafirmada a possibilidade de intervenção na vida funcional e, mesmo, na vida pessoal dos trabalhadores, através da qual formas de pensar e padróes de comportamento thes são exigidos.

No entanto, é essa mão-de-obra, alardeada pelos empresários como não tendo, na maioria, nenhuma qualificação, a que, em função dessa mesma característica, resolve os problemas de natureza funcional da empresa - realizando múltiplas atividades e substituindo os ausentes, ainda que estes desempenhem funções diferenciadas - e a que melhor se coaduna ao tipo de dominação exercido.

Dessa forma, a redução de custos da empresa começa pela mão-de-obra através do rebaixamento de salários e, ainda, pela sua substituição por máquinas em determinadas fases do processo de produção. Objetiva-se também, com a diminuição do número de empregados, a redução do conflito social. $O$ investimento dirige-se, pois, predominantemente, para a mecanização do processo produtivo e a modernizaçăo da maquinaria.

Contraditoriamente, é esse aspecto que retira desse mesmo segmento empresarial suas possibilidades de, em momentos de crise, manipular seus custos para baixo, uma vez que o investimento em ativo fixo impede essa flexibilidade.

A ideologia empresarial promove ainda a justificativa de possiveis falhas existentes na organização do trabalho, utilizando as dificuldades de sobrevivência e a fra- 
gilidade dessas empresas no mercado para obter a colaboração dos empregados e reprimir suas reivindicaçōes.

$\mathrm{Na}$ afirmação dos empresários de empreendimentos de pequeno porte, o objetivo da empresa não é exclusivamente o lucro, embora este seja indispensável à sua permanência no mercado. Consideram também como finalidade da empresa atender ao bem-estar dos empregados e obter a melhor qualidade dos produtos fabricados, por meio da aplicação de uma política de pessoal específica (individualizada e informal), que objetiva $o$ alcance de uma eficiência relativa.

$\mathrm{Na}$ realidade, a utilização da dominação patrimonialista a partir da política paternalista constitui-se num meio de busca de sobrevivência ou expansão, uma vez que possibilita reduzir custos e minimizar conflitos nesse porte de empresas. No entanto, os resultados imediatos advindos dessa política, isto é, seus aspectos considerados humanisticos, gratificam profundamente o empresariado, ao mesmo tempo que tamberm the fornecem prestígio, status e reconhecimento. Tais aspectos compensam, em parte, a falta de acesso ao poder econômico que o sistema econômico lhe nega, fazendo com que os meios utilizados para o alcance dos objetivos sejam vistos como metas finais visadas.

Essa forma de legitimar a dominação independe, portanto, de aspectos técnicos, da formação ou da personalidade do empresário. Ela é decorrente de fatores mais gerais de ordem econômica, social, política e cultural, embora, na sua aplicação, baseie-se em aspectos pessoais e emocionais que substituem grande parte das técnicas organizacionais racionais utilizadas na grande empresa.

A pequena empresa, como já foi visto, não tem condições de acesso a essas técnicas por razões de custos, de complexidade e de inviabilidade de legitimação do poder racional-legal, típico da grande empresa. Em conseqüência, seus instrumentos de controle são bastante elementares, superficiais e assumem o caráter de aferição global.

No entanto, cumprem com eficácia a função de controle da mão-de-obra, ao torná-la repressivamente dependente para que dela se obtenha a produção, de forma a resolver os problemas da empresa no mercado. Além do mais, o sentido de lealdade e dever advindo dessa dependência contribui para desmobilizar a classe em termos de reivindicações.

Foi observado na pesquisa de campo realizada para subsidiar este trabalho que o grau de intensidade desse paternalismo apresenta variações no padrão de gestão da pequena empresa.

Assim é que as empresas de pequeno porte que não possuem um grau acentuado de paternalismo caracterizando a gestão empresarial são exceções:

1. Empresas que passaram ou estão passando por uma fase de expansão, aproximando-se do porte médio, quando então começa a se instalar o processo de burocratização, embora elementar e setorializado. Um caso especial dessa transição para o porte médio é das pequenas empresas que exercem a função de complementaridade industrial. Verificou-se que as exigências de maior formalização e controle efetuadas pelas empresas contratantes (em geral, de grande porte), forçam a instalação do processo burocrático mais cedo do que nas empresas onde, esse processo ocorre mais espontaneamente por exigência do acúmulo de incumbência da direção.

2. Empresas planejadas e dirigidas por técnicos em produção e administração, que procuram utilizar algumas técnicas operacionais de melhor divisão do trabalho, melhor atribuição de tarefas, recrutamento e seleção baseados primordialmente na habilitação profissional etc.

3. Empresas estruturadas como reação à política paternalista e como tentativa de implantação de um modelo semelhante e adaptado, em alguns aspectos, ao conhecido e muito difundido modelo taylorista destinado às grandes empresas.

De modo geral, a pequena empresa industrial apresenta um padrão de gestão paternalistá modernizado, uma vez que, atualmente, o modelo tradicional vem, cada vez mais, se inviabilizando. Os problemas de custos, as reações da classe trabalhadora, que passa a aspirar por relações mais formais de traballho e, ainda, a recessão econômica, que, ao provocar o desemprego, acarreta a diminuição das reivindicaçōes da classe operária e a limitação de suas aspiraçōes a prioritariamente manter seu emprego, concorrem para essa transformação. Todos esses efeitos determinam o corte de benefícios tradicionalmente concedidos aos empregados, assim como reduzem ao mínimo o número de beneficiários dessa política paternalista.

Além do mais, na atualidade, as medidas governamentais relativas à política salarial (determinação do quantum de aumento, reajustes dados por categoria de operários segundo o gênero de indústrias etc.), e à instituição do FGTS desviam o conflito, direcionando-o ao governo e contribuindo para a redução e desmobilização das reivindicações operárias a nível das empresas.

Neste sentido, as preocupaçōes empresariais relativas a conflitos (que na pequena empresa ocorrem "cara a cara"), reduzem-se, o que permite que suas atençōes se voltem mais para os aspectos gerenciais de caráter individualizado.

Quanto às atitudes de falta de reconhecimento que os empresários atribuem aos operários, desmotivando a extensão da política paternalista, significam, na verdade, a afirmação de direitos empregatícios e a negação de uma dependência a nível pessoal e profissional.

Continuam sendo paternalistas tradicionais apenas os empresários das pequenas empresas de menor tamanho, bastante antigas no mercado e cuja experiência na função empresarial também advém de longa data (fundadores ou filhos de fundadores).

É, pois, essa forma de legitimação, determinando um modelo básico organizacional de estrutura do poder, que possibilita a manutenção da pequena empresa no sistema econômico, permitindo, às vezes, até sua expansão, embora não explique questões de desempenho da empresa no mercado, quando então outros elementos devem ser avaliados.

Essa expansão, em geral, só ocorre dentro de sua própria faixa de tamanho, pois, embora a pequena empresa seja produtiva, sua permanência no mercado depende acentuadamente da situação específica da indústria à qual pertence. Sua condição de produtor complementar e/ou suplementar à grande empresa, nas estruturas de mercado, mais do que a pequena dimensão de seu capi- 
tal, impede-lhe a obtenção de excedentes líquidos a longo prazo, limitando, portanto, sua expansão de um porte para outro; salto este que muito raramente se dá.

As considerações apresentadas quanto ao papel das pequenas empresas deixam bem claro que interessa ao sistema capitalista, na sua atual etapa de desenvolvimento nas economias periféricas - para que o próprio capital possa se reproduzir e ampliar - a presença de pequenas empresas no mercado, não só pelos motivos econômicos já explicitados, mas também do ponto de vista político de ampliação e fortalecimento de uma classe vital para o modo de produção - a classe dos proprietários dos meios de produção.

Assim sendo, a estratégia de fortalecimento da pequena empresa objetivando sua sobrevivência, evidentemente dentro dos espaços determinados na estrutura de mercado e sem, portanto, estabelecer concorrência ou dificuldades para as empresas maiores, poderá receber o apoio do grande capital, pois, indiretamente, o estará beneficiando, na medida em que as funções das grandes empresas no mercado são complementadas e/ou suplementadas pelas menores.

É a ampliação desses espaços ou a abertura de novos, ou ainda a consecução de prioridades no acesso aos recursos financeiros destinados ao fomento do setor industrial, que conflitaria com os interesses do grande capital e que poderia significar "bandeiras de luta" do pequeno empresário em determinadas fases de expansão do sistema econômico.

A política de apoio às pequenas empresas, portanto, deve, no mínimo, assegurar que não se restrinjam os espaços reservados à sua atuação, principalmente nessa fase de incentivo e disseminação das multiplantas das grandes empresas.

A assessoria técnica gerencial, então, torna-se um elemento eficaz no sentido de adequar a pequena empresa à estrutura de mercado, desde que orientada para considerar como pressupostos dessa ação:

a) as funções das pequenas empresas na estrutura de mercado;

b) suas condições de sobrevivência e/ou expansão nesse mercado;

c) as características de sua estrutura de poder.

Inicialmente, torna-se importantíssimo que a assesoria técnica gerencial seja planejada a partir e ao nível do conhecimento das diferentes estruturas de mercado e dos grupos de indústria que se articulam no sistema econômico. Somente desta forma ter-se-á exatamente determinados, em um dado momento, os papéis e as perspectivas das empresas de pequeno porte em cada estrutura de mercado e grupo de indústria. Este planejamento determinará as prioridades de atuação em função do desenvolvimento do processo de industrialização e suas características relativas a gêneros industriais, produtos, processos etc.

A partir desse diagnóstico inicial, o caráter do assessoramento poderá se destinar ao aperfeiçoamento do desempenho da pequena empresa no mercado, instrumentalizando seus administradores no sentido de melho- rar suas formas de controle do processo produtivo, sem alterar basicamente a forma de legitimaçã̃o da estrutura de poder patrimonialista vigente, a não ser nas etapas de transição da pequena empresa para média, quando a função da assessoria deverá se prender à orientação da instalação e desenvolvimento do processo de burocratização, a fim de que este seja iniciado ordenadamente e sem atropelos.

Quer diagnosticando a sobrevivência ou a expansão, quer adequando a empresa à sua função, quer planejando e orientando a transição, nada pode ser mais funesto do que utilizar métodos e técnicas das grandes para as pequenas empresas. Muitas vezes não há possibilidade nem mesmo de adequação. $\mathrm{E}$ isto não consiste apenas em problemas de custos e complexidade, mas, essencialmente, da quebra de um padrão de legitimação de funcionamento, que não tem condições de ser substituído por outra modalidade.

Percebe-se assim que, de imediato, o caráter paternalista não pode ser eliminado totalmente enquanto elemento básico para assegurar a dominação. Tem-se, no entanto, observado que suas características vêm-se alterando por influência das condiçбes de desenvolvimento do processo de industrialização do país. Este é, pois, o momento para intensificar esse processo de descaracterização do pał̧ernalismo tradicional, no sentido de combater seu caráter repressivo de dependência ampla, procurando dar ênfase à organização, representatividade e reivindicação das várias classes sociais inseridas no processo de desenvolvimento do capitalismo.

Aspecto também prioritário é a preparação do empresariado no sentido da sua conscientização sobre $o$ processo de desenvolvimento econômico e político do país, suas possibilidades de participação e formas de reivindicação, que necessitam ser elaboradas a partir da análise do papel da pequena empresa, do conhecimento do papel de seu segmento de classe e de suas limitações. Ao mesmo tempo, a postura de valorização da experiência e atuação empresarial é indispensável, uma vez que a classe tem conseguido criar e fazer sobreviver uma série de empreendimentos, que embora carentes de técnicas de controles ou de agilização dos processos decisórios ou de criação de mecanismos de planejamento, asseguram o domínio necessário ao alcance dos objetivos.

O sentido mais geral ta assessoria técnica gerencial, no entanto, deve ser muito bem discutido.

É evidente que a origem das relações de trabalho dentro da empresa advém da estrutura social da sociedade capitalista. As relações fundamentais aí estão, assim como a ideologia empresarial, funcionando claramente para mascarar o caráter de dominação dessas relações ou abafar tensões e conflitos emergentes. Internamente, porém, características pessoais e de grupos se entrechocam, fornecendo peculiaridades a cada forma organizacional, cujo funcionamento, a nível da assessoria, deve ser conhecido e aproveitado no sentido, também, da explicitação das necessidades humanas dentro do processo de trabalho. Não no sentido ilusório e mascarador da realiadade, da proposição de um equilíbrio de poder entre capital e trabalho. Mas, sim, pautando-se pela realidade das relações de trabalho no sistema capitalista - em que o trabalho subordina-se ao capital -, procurar melhor dispor o ser humano dentro do processo de trabalho e, a partir de suas reivindicaçסes, tentar compor uma or- 
dem de funcionamento que possa também redundar em melhoria da produtividade.

Essa questão da alienação do trabalhador é que necessita ser muito bem ponderada nesse contex to.

O que já está se divisando é que a subordinação com características de extrema dependência não é mais aceita pelos operários porque se começa a perceber o uso dessa forma para se proceder ao mascaramento da contradição fundamental existente entre capital e trabalho.

O bom patrão não é mais o que se diz amigo, mas o que remunera bem a mão-de-obra, respeita e considera seus direitos, inclusive os de reivindicação.

$O$ efeito-demonstração da organização de alguns segmentos da classe operária - especialmente nas grandes empresas de alguns gêneros industriais mais dinâmicos na atualidade - e da divulgação de suas reivindicações começa a se refletir, embora de modo ainda bastante incipiente, nas pequenas empresas, provocando algumas reações ao caráter da dominação paternalista.

Enquanto, porém, as atuais características do modelo de desenvolvimento brasileiro vigorarem, difícil se torna falar em mudança do tipo de inserção das pequenas empresas nesse processo e do tipo de estrutura de poder vigente. Talvez alguns grupos de indústrias, incluídos nos setores mais dinâmicos ou mais modernos da estrutura econômica, tenham mais possibilidades de alterar as condições das suas pequenas empresas, modernizando-as, e daí encaminhá-las para a superação da forma organizacional de caráter acentuadamente paternalista.

A transformação que já vem ocorrendo no padrão de gestão da pequena empresa é um indício das mudanças que se processam a nível da sociedade global.

$O$ que deve ser lembrado, no entanto, é que a presença de fatores de ordem subjetiva na administração de pequenas empresas - que, para melhor sobreviverem, aparentemente deveriam se investir da forma mais racional e eficaz dentro do sistema capitalista: a forma organizacional burocrática - pode, no máximo, ser controlada ou reduzida, mas é inevitável e indispensável, dadas as condiçzes econômicas, sociais, políticas e culturais do processo de industrialização do país.

* Este artigo faz parte de um trabalho mais amplo apresentado na Escola de Administração de Empresas de São Paulo da Fundação Getulio Vargas (EAESP/FGV), como requisito para a obtenção do título de Mestre em Administração, em junho/83.

${ }^{1}$ Cf. Gonçalves, Carlos E. do Nascimento. A Pequena e média empresa na Estrutura industrial brasileira (1949-1970). Campinas, IFCH/Unicamp, tese de doutoramento, 1976, 2 v., p. 24, mimeogr.

${ }^{2}$ Cf. Cardoso, Fernando Henrique. Empresário industrial e desenvolvimento económico no Brasil. São Paulo, Difusão Européia do Livro, 1964, p. 40.

${ }^{3}$ Weber, Max. Economia y sociedad. México, Fondo de Cultura Económica, 1974, 2 v.

${ }^{4}$ Cf. classificação de Max Weber em Economia y sociedad. op. cit.

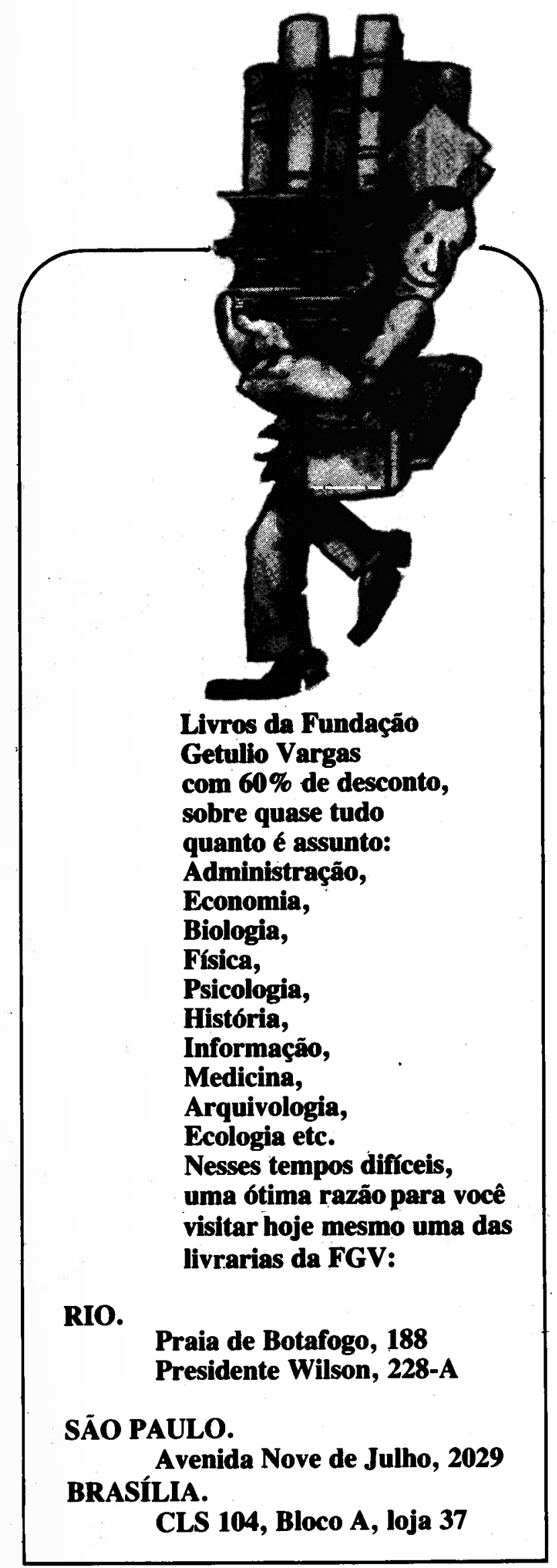

